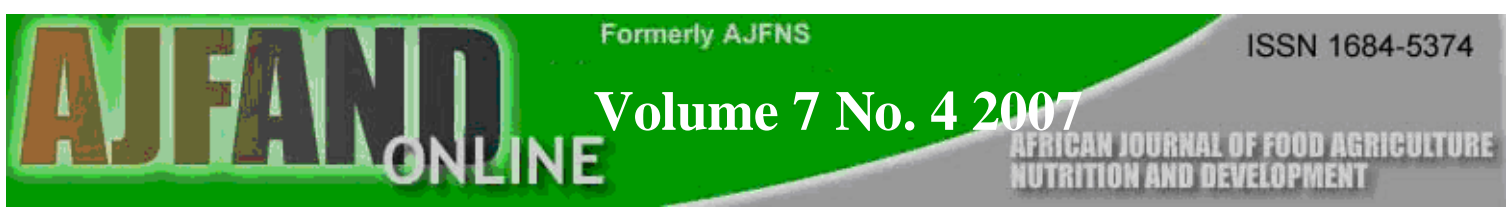

\title{
Opportunities for Increased Production, Utilization and Income Generation from African Leafy Vegetables in Zambia
}

\section{By}

Dickson Nguni*1 and Godfrey Mwila ${ }^{2}$

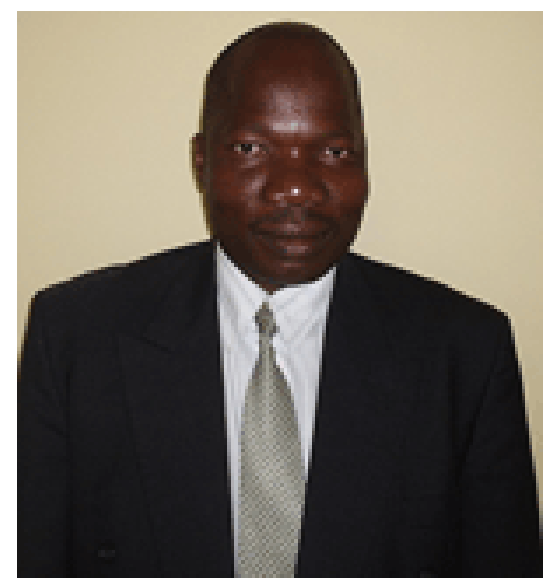

Dickson Nguni ${ }^{\star 1}$

"Corresponding author Email: dicksonnguni@yahoo.co.uk

${ }^{1}$ National Plant Genetic Resources Centre, Zambia Agriculture Research Institute,B7, Chilanga,Zambia. House No. 60, Mount Makulu, Off Kafue Road.

${ }^{2}$ SADC Plant Genetic Resource Centre, P/B CH99, Lusaka, Zambia.SPGRC along Great East Road, Chalimbana.Email- mwilagodrey@yahoo.co.uk 


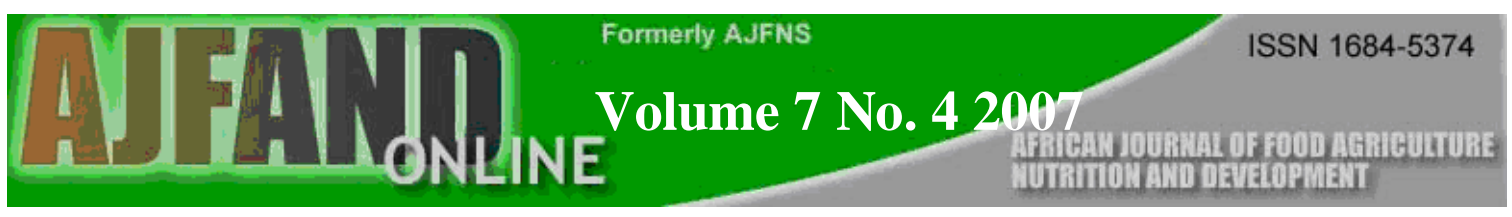

\section{ABSTRACT}

In order to promote the production and marketing of African Leafy Vegetables (ALVs) and help realize their potential as sources of food and income, a case study was undertaken under the IPGRI programme on ALVs. The study was aimed at determining the priority ALVs and assessing their status in terms of genetic diversity, production, processing and marketing through a household survey. Three communities of Hoffmeyer, Subcentre and Chikumbi in Nyimba, Siavonga and Chibombo districts respectively were covered. Information was gathered from 280 households across the communities through participatory rural appraisal using guided household interviews and focused group discussions. Amaranthus spp. Wild spinach (English) Bboonko (Tonga), Libondwe (Lenje), Bondwe (Nyanja); Cleome gynandra Cat's whiskers, spiderplant (English), Shungwa/ Luyuni-yuni (Tonga), Lubanga (Lenje), Suntha (Nyanja); Abelmoschus esculentus, Okra (English), Mudelele/ Mutezi (Tonga), Delele/ Mulembwe (Lenje), Delele (Nyanja); Brassica carinata, Ethiopian Mustard (English) Tanta a chulu/ Chishu chituba (Tonga), Mupilu/ Nchembele (Lenje), Mupilu (Nyanja) and Cucurbita spp., Pumpkin (English) Bboobbo, Lutanga, Muchile (Tonga), Buchisa bwa nyungu (Lenje), Chiwawa, Mthopo (Njanja) were identified as priority ALVs.

It was found that within species variability based on morphological markers of the target ALVs was generally low except for Abelmoschus esculentus and Cucurbita spp which had more than three known varieties. Although $63 \%$ of households cultivated both ALVs and exotic vegetables, $33 \%$ of the households cultivated ALVs while only $4 \%$ exclusively grew exotic vegetables. Farm saved seed for all ALVs except Abelmoschus esculentus was used by $81 \%$ of households across communities while $10 \%$ obtained their seed from neighbours/relatives within their communities. Direct sowing was the commonest planting method while the application of organic manure to the crop was prominent in Subcentre followed by Chikumbi. Application of mineral fertilizers to ALVs was uncommon practice except in Abelmoschus esculentus. It was revealed that the most preserved ALVs were Abelmoschus esculentus and Cucurbita spp. Open markets and supermarkets in Lusaka sold ALVs such as Abelmoschus esculentus, Amaranthus spp and Cucurbita spp. The main sources of these vegetables in Lusaka were local farmers in the peri-urban areas of the town. A total of 33 different recipes and eleven preservation methods for ALVs were documented across communities while 7 recipes were documented from commercial restaurants. The ALVs play an increasing role in the diets and as source of income for many households and efforts required for stimulating production include improvements in access to improved varieties and availability of urban markets.

Keywords: Amaranths, Cleome, Okra, Cucurbits.

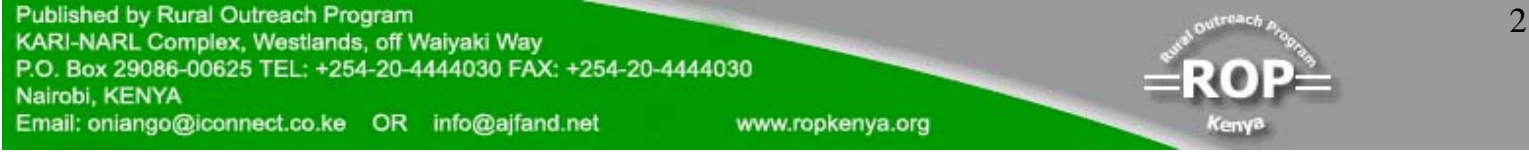




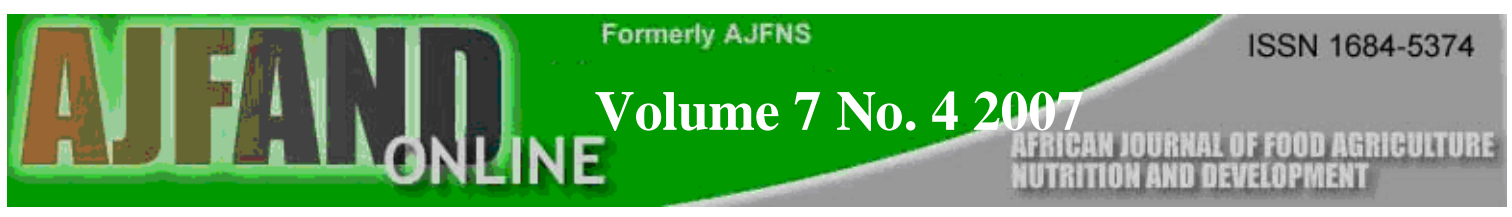

\section{INTRODUCTION}

African Leafy Vegetables (ALVs) are traditionally known plants whose leaves (including immature green pods and flowers) are socially accepted, used and consumed [1]. In Zambia, ALVs occur as cultivated and semi-cultivated crops or weedy and wild plants, with ecological, social and cultural values, playing a significant role in the day to day food and nutritional requirements of local people mainly in rural areas, but more increasingly also in urban areas. It is generally accepted that there are cultural differences between rural and urban communities in lifestyles including food habits. In the urban setting the status of ALVs is affected by the changing socio-cultural values and attitudes.

The ALVs in Zambia include major local traditional vegetables such as Amaranthus spp., Cleome gynandra, Abelmoschus esculentus, Brassica carinata and Cucurbita maxima. There are various other vegetable species occurring locally which are utilised to varying degrees. Most of these species occur either as semi-cultivated or tolerated weeds. The tolerated weeds are those plant species that frequently and extensively encountered around human dwellings and in farmland as a result of large scale protection of because they have been left as volunteer seedlings during cultivation of other crops [2]

The term "local vegetables" can also include leaves of some crop species cultivated widely in Zambia and elsewhere for their pods, roots, or tubers. Leaves from beans and cowpeas are important vegetables [3]. Vegetables are a basic component of the Zambian diet that accompanies the starch staple, Nshima, which is a thick porridge made from either maize or other cereal meal. As indicated in the survey findings [3], in most households vegetables are served at least once a day as the main or only relish.

Processing and Preparation of ALVs is a critical factor in the promotion of their production, consumption and conservation of these vegetable species. Although different communities in Zambia have their own traditional methods for processing and preparation of these vegetables, there has been limited documentation of such information. Changes in the food cultures that have taken place over the years pose threats to the continued existence of local knowledge pertaining to such food preparation and processing methods. The promotion of exotic vegetables such as cabbage or spinach has masked the value of local food cultures which over years threatens the continued existence of local knowledge pertaining to preparation and preservation of ALVs.

In order to promote the production, marketing and utilization of African Leafy Vegetables (ALVs) and help to realize their potential as sources of household food and income, a survey was undertaken under the IPGRI programme on ALVs

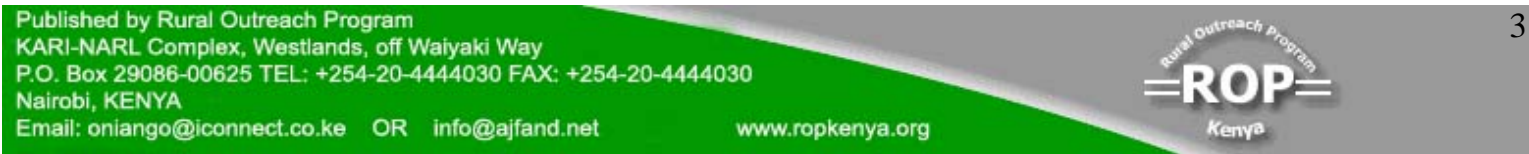




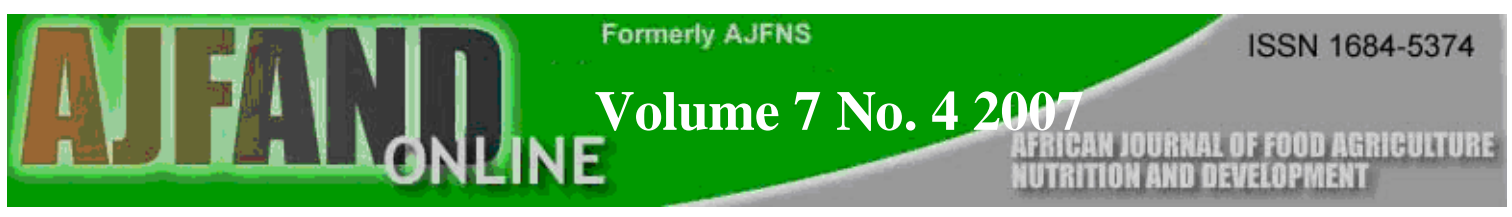

covering Hoffmeyer, Subcentre and Chikumbi communities with the aim of determining the priority ALVs and assessing their status in terms of genetic diversity, production, processing and marketing.

This article highlights the activities undertaken under the above studies, the major findings in terms of opportunities for promotion of ALVs and recommendations made on action required in terms of interventions to promote the production, marketing and consumption of ALVs in Zambia.

\section{METHODOLOGY}

Two studies were undertaken; the household survey and the documentation of processing and preparation of ALVs were conducted in Hoffmeyer, Subcentre and Chikumbi communities of Nyimba, Siavonga and Chibombo districts respectively (Figure 1). Each of the selected communities was equivalent to an Agricultural Camp, which is an official designated unit for the purposes of delivery of agriculture extension services.

Hoffmeyer is located in Eastern Province about $380 \mathrm{~km}$ from Lusaka lying in AgroEcological Zone (AEZ) II with mean annual rainfall of about $700 \mathrm{~mm}$. The Subcentre is located in Southern Province about $130 \mathrm{~km}$ from Lusaka lying in Gwembe Valley within the Agro Ecological Zone I, characterized by a semi-arid and dry sub-humid climate with mean annual rainfall of $650 \mathrm{~mm}$, while Chikumbi is located in Central Province about 20km north of Lusaka, lying in Agro-Ecological Zone II, which is characterized by mean annual rainfall of between $800-1000 \mathrm{~mm}$. 


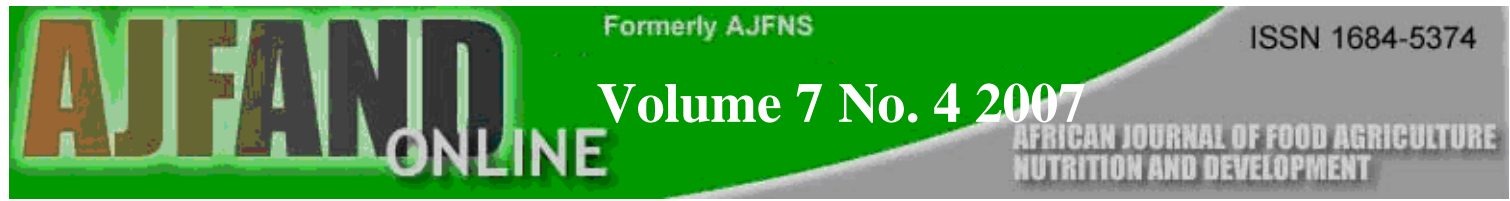

Figure 1: Location of the sites for the household survey

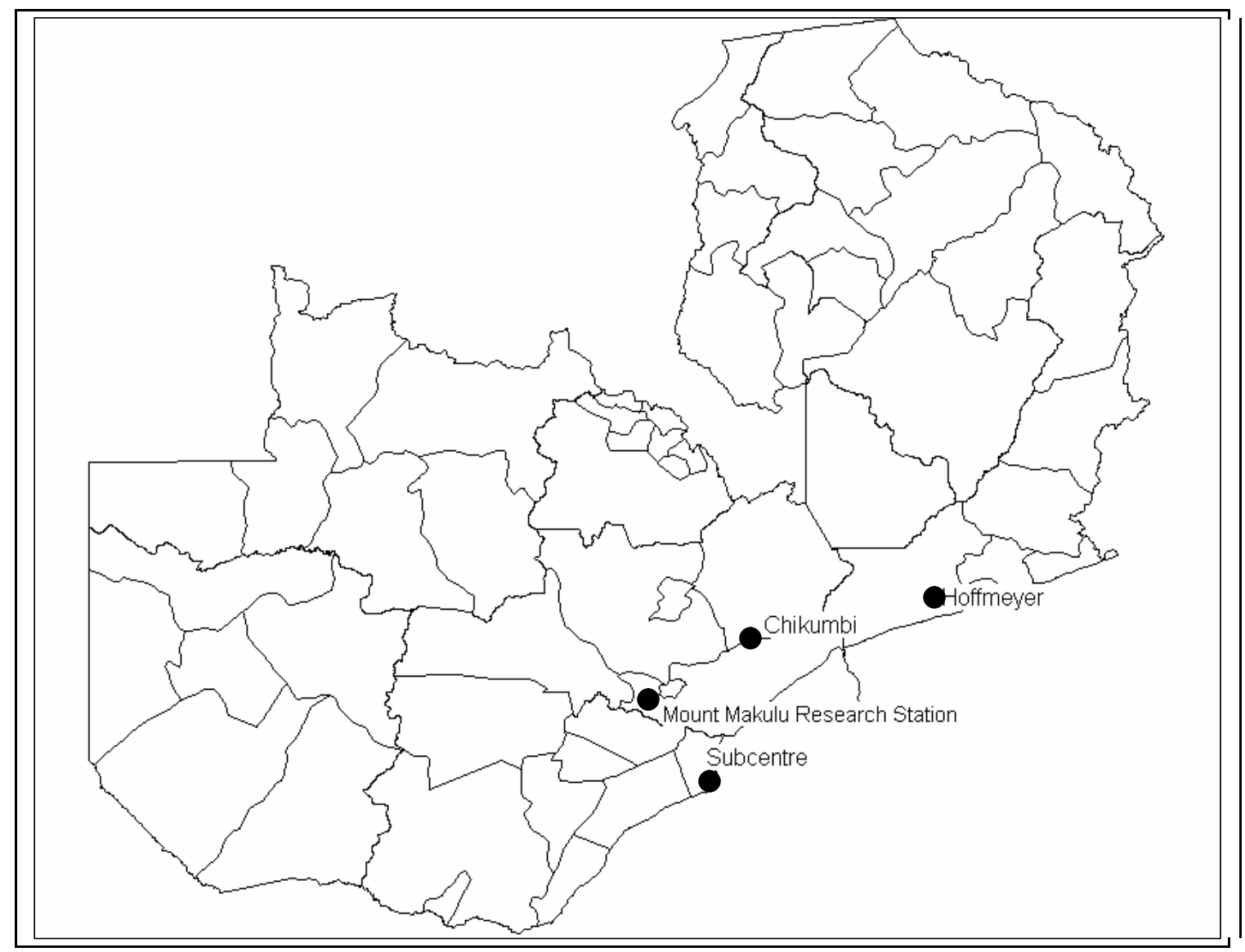

The planning and implementation of the household survey was carried out by a multidisciplinary team involving personnel from the National Plant genetic Resources Centre, Vegetable Research Team, Food Technology Unit of the National Institute for Scientific and Industrial Research (NISIR), Agricultural Extension and a local NGO involved in community resource conservation and use. Local community leaders were co-opted to work with the core team in the field and were instrumental in facilitating access to the communities and with interpretation where necessary. Data and information was collected using participatory rural appraisal and more specifically a semi-structured questionnaire was administered targeting heads of households. Further information was collected through focused or guided group discussions (Figure 2).

The questionnaire was designed to capture data and information on demographic, household resources, genetic diversity of ALVs, cultivation practices, seed supply systems and storage, post harvest handling and preparation. A total of 280 
households across communities were sampled. Of the total number of households sampled, 89 were from Chikumbi, 95 from Subcentre and 96 from Hoffmeyer. Analysis of quantitative data was done by calculating frequencies and percentages of various responses and the summary information presented in form of tables and charts.

Figure 2: Information gathering through Focus Group Discussion in Hoffmeyer.

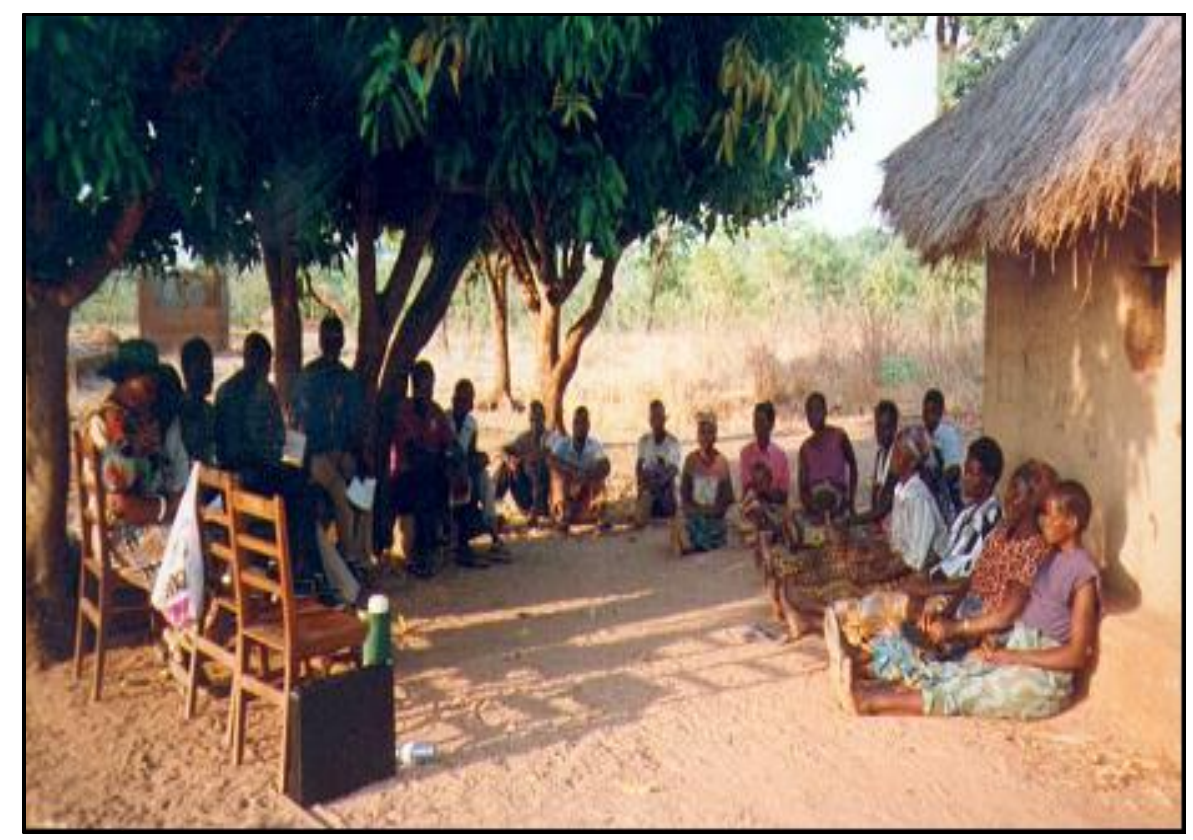

The documentation of the processing and preparation methods was conducted by a team of technical staff from the Food Technology Research Unit (FTRU) of NISIR, National Plant Genetic Resources Centre of Zambia Agriculture Research Institute and Department of Field Services of MACO. A guided participatory approach, Focus Group Discussions (FGD), using a checklist was used to obtain information. In addition to FDG, supervised cooking demonstrations using traditional recipes were conducted by local women in each of the communities to facilitate the collection of detailed data. Further information on preparation and processing of fresh and preserved ALVs was also obtained from one of the hotel restaurants in Lusaka. 


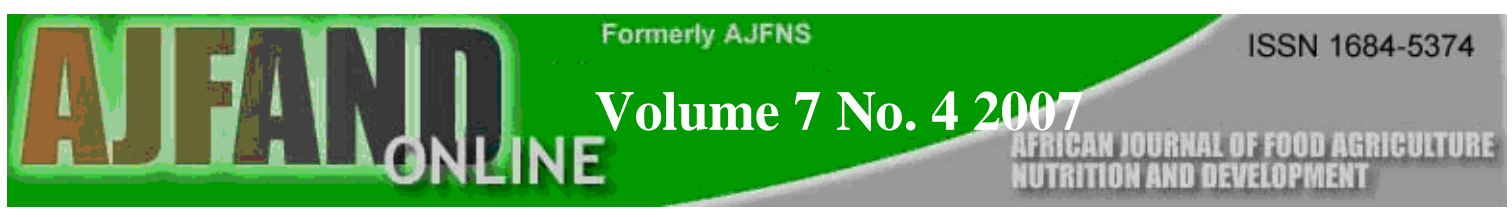

\section{FINDINGS}

\section{CULTIVATION AND VARIABILITY OF AFRICAN LEAFY VEGETABLES}

From the household survey it was found that most households, in the target communities, cultivated both exotic and African Leafy Vegetables (ALVs). Across the communities about 33 percent of the households cultivated only ALVs while 4 percent only cultivated exotic vegetables compared to 63 percent who grew both. In general it can be said that the cultivation of ALVs is more common in the surveyed communities compared to exotic vegetables.

Comparison among target communities showed that Sub centre had the highest number of households cultivating only ALVs (42\%), followed by Chikumbi $(27 \%)$. In Hoffmeyer community $12 \%$ of households cultivated exotic vegetables only compared to Sub centre and Chikumbi with 1 and 2 percent respectively (Figure 3).

Figure 3: Type of vegetables grown in the three target communities

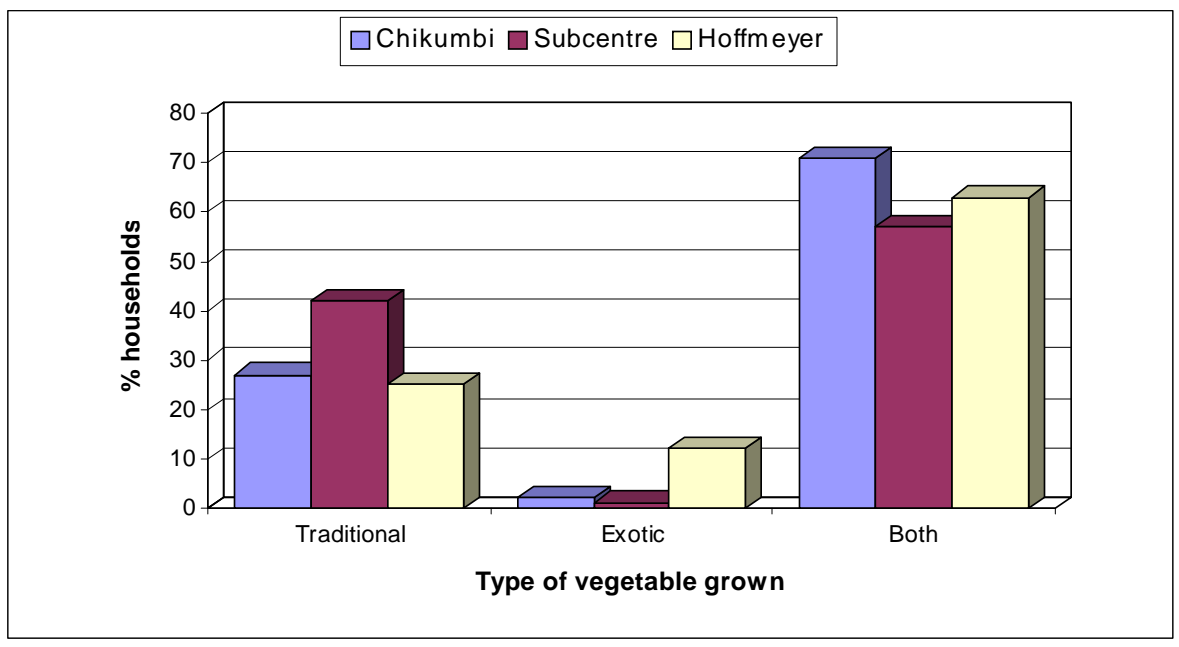

About $57 \%$ of the households across the target communities considered some ALVs as semi-cultivated while $42.5 \%$ considered them as cultivated crops. A small percentage of households $(1.8 \%)$ solely depended on gathering them as weedy and semi-wild species. The ALVs considered as semi-cultivated, weedy and wild are in most cases Amaranthus spp and Cleome gynandra.

In general the area planted to vegetables is very small, with about $48 \%$ of the household cultivating less than 0.001 hectares. In general more land was allocated to ALVs than exotic species across the communities. 


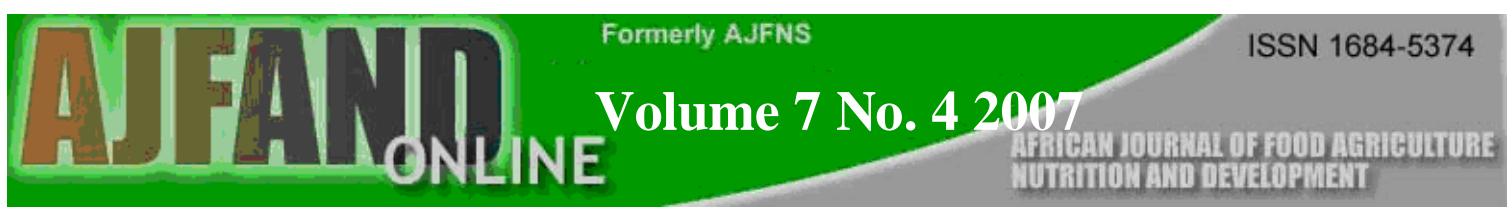

The genetic diversity of ALVs as indicated by the number of known varieties was generally low. Although a few households indicated knowing up to 5 different varieties for some of the priority species, more than 90 percent of the households knew only 2 varieties. Abelmoschus esculentus, followed by cucurbita spp. seems to have more genetic diversity while Cleome gynandra (Cleome gynandra) showed the least diversity with only 3 varieties known in all the communities.

\section{SEED SUPPLY SYSTEMS AND ON-FARM SEED MAINTENANCE OF ALVS}

The survey revealed that about $81 \%$ of households across the communities use own-saved seed to grow ALVs while about $10 \%$ obtain them free of charge from neighbours and relatives. Only a small proportion of households (1\%) obtained seed from outside their own communities. This is an indication of limited trade involving seeds of ALVs. The case of Abelmoschus esculentus, it was found that there was a higher incidence of seed being obtained from outside the community compared to other species. This is more pronounced in the Subcentre community.

Results further indicate a higher incidence of seed purchase from within communities for Brassica carinata (12\%), while being negligible for other species. The practice seems to be common in Subcentre and Hoffmeyer.

Figure 4 gives a picture of how seed of priority ALVs is sourced in the three different target communities. In general there was more seed exchange among neighbors or relatives in Chikumbi followed by Hoffmeyer. Free seed exchange within the community was least common in Subcentre, which had the highest incidence of households purchasing seed from within the community.

Figure 4: Source of seed for ALVs in the three target communities

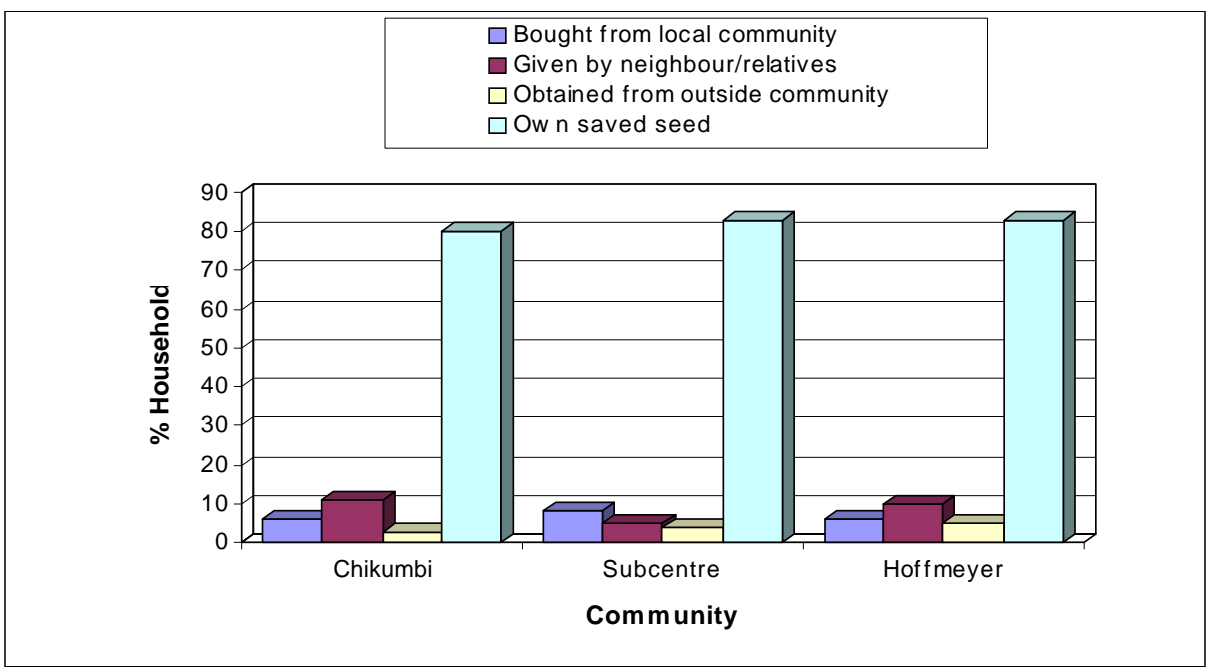




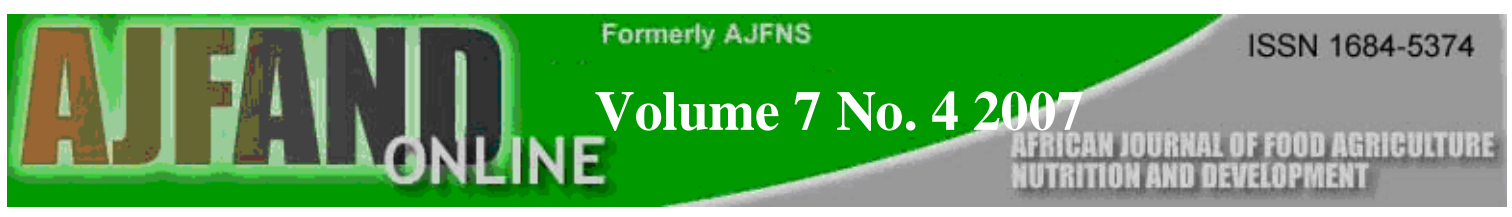

The majority of households (42\%) reported sourcing improved seed of ALVs from own farm-saved seed, while 30 percent obtained seed through purchasing from outside their local community. The practice of obtaining improved seed of ALVs from own farm-saved seed was commonest in Sub centre $(60 \%)$ followed by Hoffmeyer (54\%) with Chikumbi being the least $(12 \%)$. On the other hand Chikumbi had the highest proportion of households sourcing seed within the local community through purchasing (36\%). Both Sub centre and Hoffmeyer had low incidences of seed purchase.

The survey also revealed that generally seed of all ALVs was being stored in sealed tins after harvesting and processing and kept in homesteads. In a few cases (3\%) seeds of Cleome gynandra and Abelmoschus esculentus, were stored by hanging over the fire place. The African calabash was also used in a few cases especially in the storage of seeds of Cucurbita spp (6\%). No chemical treatment was reported. The use of Ash treatment was reported in the storage of seeds of Abelmoschus esculentus by some households (12\%).

In terms of storage period it was found that seed was generally being stored for a period of less than one year from harvest to the next planting season. Some households, however, reported storing seeds of Abelmoschus esculentus and Cucurbita spp for over one and two years.

\section{LOCAL CULTIVATION PRACTICES AND CROPPING SYSTEMS USED}

Information gathered from the survey indicates that the five priority ALVs have been under cultivation in the target communities for more than 20 years.

The commonest planting method for Amaranthus spp. and Cleome gynandra was found to be direct seeding by broadcasting. This is more prevalent in Cleome gynandra (76\%). Direct seeding in rows or lines was found to be the commonest planting method in Abelmoschus esculentus, Cucurbita spp. and Brassica carinata. Cucurbita spp.were also found to be planted in hills either in rows/lines or at random.

Transplanting followed by planting in rows/lines was found to be commonest in Brassica carinata. Transplanting was however, found to be a rare practice among the households across the communities.

Most households prefer to plant or grow these priority ALVs during the warm and wet season, which is from late November to early April. In a few cases Amaranthus spp. was planted in the hot dry season under irrigation. In Subcentre and Chikumbi Brassica carinata was also planted in the hot dry and cool dry

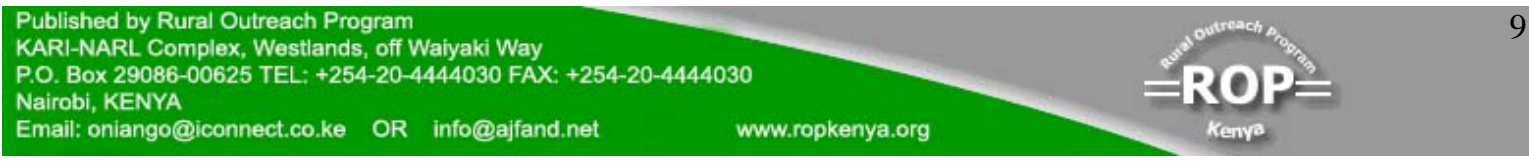




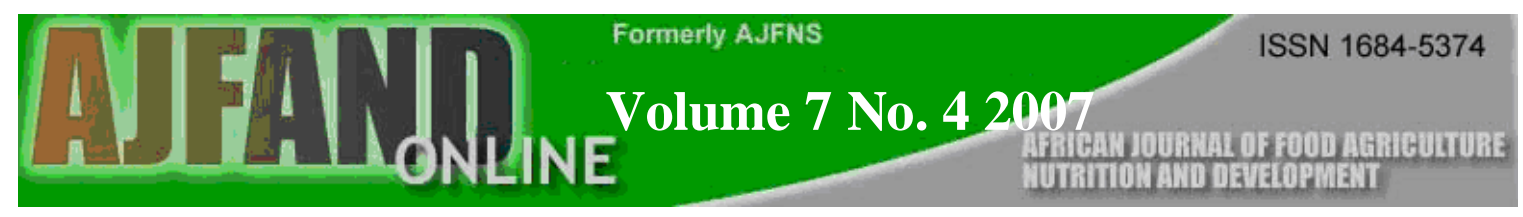

seasons under irrigation. Cucurbits were also reported to be grown in the hot dry season in all the communities.

A number of cropping systems, including inter-row, mixed and sole cropping are used in the cultivation of ALVs. The commonest cropping systems were found to be mixed and sole cropping. Sole cropping was more prevalent in Abelmoschus esculentus followed by Brassica carinata.

There is more inter-row cropping practiced in Cucurbita spp. cultivation than any other ALVs. Inter-row cropping was being practised by some households in Abelmoschus esculentus, Cucurbita spp. and Brassica carinata. This practice was, however found to be commonest in Abelmoschus esculentus followed by Cucurbita spp. (Figure 5)

Figure 5: Comparison of cropping systems used for some ALVs species.

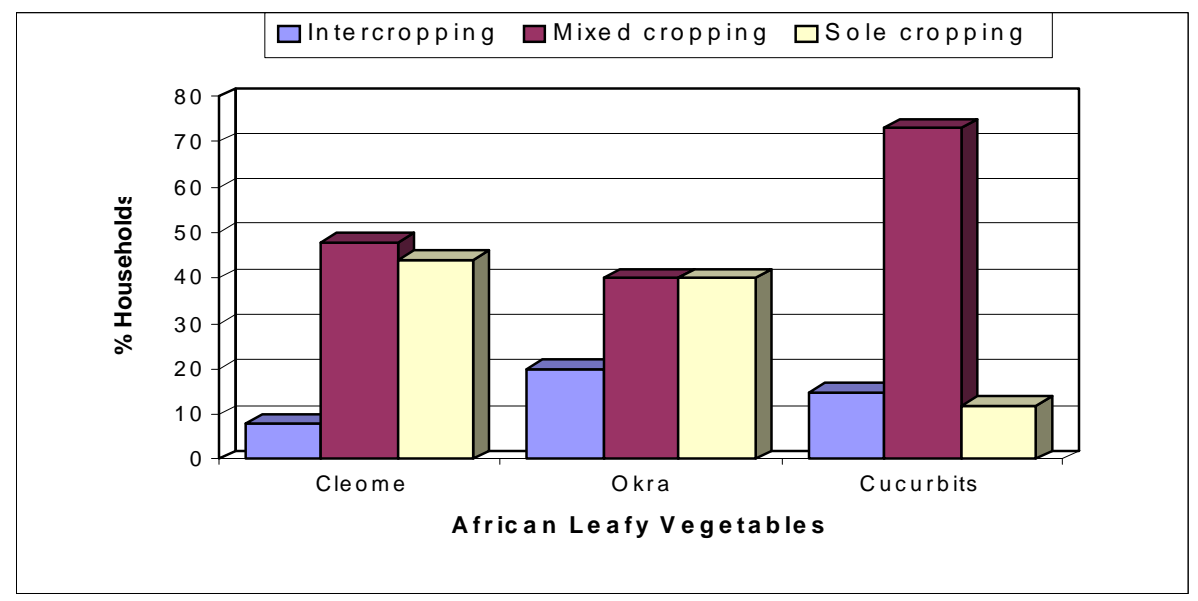

\section{HARVESTING, PROCESSING AND PRESERVATION METHODS}

Most of the households indicated that they only harvested leaves of Amaranthus spp. $(84 \%)$ and Brassica carinata $(88 \%)$ for consumption. Only in a few cases were leaves with tender stems harvested for Amaranthus spp. (13\%) and Brassica carinata (7\%). It was also revealed that mainly tender leaves of Brassica carinata were harvested, as older leaves tended to be tough and bitter making them unpalatable.

In the case of Cleome gynandra, leaves were the most harvested part of the plant accounting for $64 \%$ of the households, followed by leaves and stems $(21 \%)$ and a small proportional harvested leaves and flowers (6\%). 


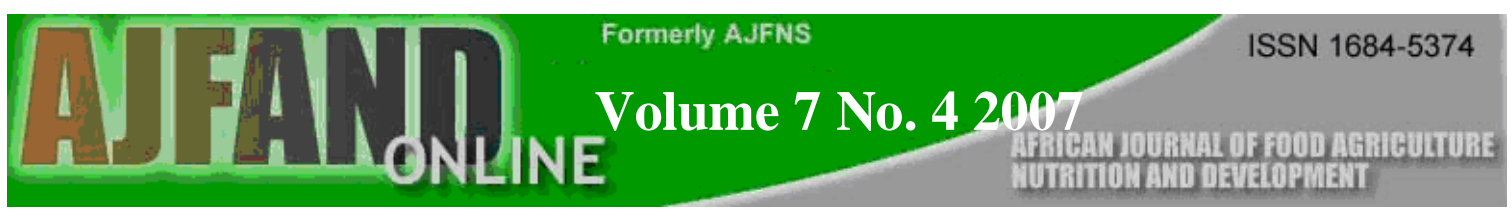

For Abelmoschus esculentus the commonest harvested parts of the plant across communities were leaves and flowers (41\%). This practice was more prevalent in Chikumbi (51\%) and Hoffmeyer (44\%). In Subcentre $22 \%$ of the households harvested both fruits and leaves. Across the communities only $11 \%$ of the households harvested leaves only. Harvesting of fruits only was common in Chikumbi.

The most harvested parts of the plant for Cucurbita spp. were leaves and flowers $(52 \%)$, followed by leaves only (33\%). In a few cases stems together with leaves and flowers are harvested. Most of the harvested flowers are males as female flowers are deliberately left to bear fruits.

It terms of responsibility for harvesting of the vegetables, it was largely women (over $60 \%$ ) who were involved followed by children and mainly girls (about $30 \%$ ) except for Abelmoschus esculentus and Cucurbita spp. where children accounted only for 24 and 23 percent respectively.

In over $50 \%$ of the cases households indicated that they chopped the vegetables before drying. This was however less prevalent in Amaranthus spp. and Cleome gynandra where 40 and 16 percent respectively dried the whole leaf. Chopping was found to be more prevalent in Cleome gynandra (80\%), Abelmoschus esculentus (89\%) and Cucurbita spp (74\%) (Figure 3.11). In cucurbits, some households reported removal of the outer fibrous material from the leaves before chopping either for direct cooking or drying.

Majority of households (69 and 95 percent) indicated drying Amaranthus spp. (69\%) and Abelmoschus esculentus (95\%) without blanching. Abelmoschus esculentus is generally not blanched owing to its mucilaginous nature. In the case of Cleome gynandra, Brassica carinata and Cucurbita spp. about $60 \%$ indicated that they blanched the vegetables before sun drying. Blanching of leafy vegetables improves colour and carotene retention due to inactivation of enzymes but causes losses of ascorbic acid (Vitamin C).

Reed mats or sacks were the common drying surfaces. In $46 \%$ of the cases drying surfaces are placed on raised platforms while the rest spread them on the ground. Putting drying surfaces on platforms is done in order to protect vegetables from domestic animals and dust. The vegetables may, however, still be prone to insect infestation. A small proportion of households (5\%), mainly from the Sub centre community, dried vegetables on rooftops. Naturally occurring flat stone surfaces are taken advantage of and used as drying surfaces where these are found. The drying process is said to be faster on the stone than the mat or sack. 


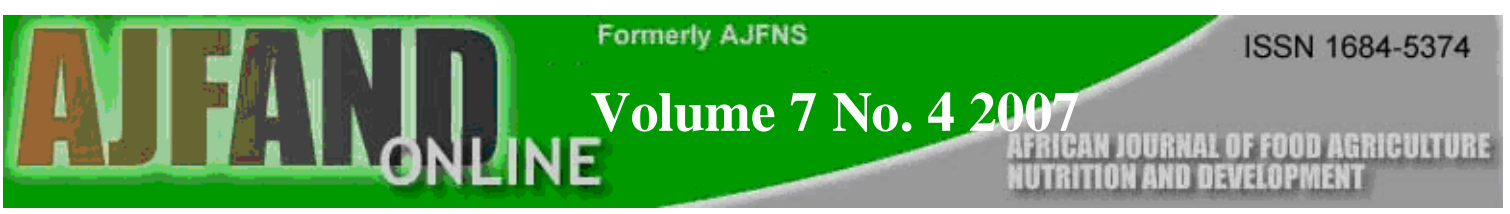

Over $50 \%$ of the households reported that the preserved vegetables lasted for more than 4 months while about 30\% indicated that vegetables lasted between 2 to 4 months. It is therefore clear that the later group runs out of preserved vegetables before the next rain season as the dry period lasts for about 6 months. The preserved vegetables are used for both own consumption and selling. About $50 \%$ of the households preserved vegetables for both selling and own consumption while $40 \%$ used the preserved vegetables only for consumption. Few households, less than $5 \%$, preserved vegetables solely for sale.

The households indicated that the quantity of preserved vegetables varied from year to year and depended on yields or amounts harvested.

\section{PREPARATION AND CONSUMPTION OF ALVs}

For both fresh and dried vegetables the survey results (Figure 6) showed that over $50 \%$ of the households had knowledge of 2-4 preparation methods of all vegetable types across the communities visited except for dried Abelmoschus esculentus where the majority (56\%) indicated that they used only one method of cooking. The common method of cooking was boiling (over 60\%) and most of the households $(60 \%)$ took less than 30 minutes to cook these vegetables except for Cleome gynandra where $44 \%$ and $36 \%$ took between $30-60$ minutes and more than 60 minutes respectively. Households were also asked to indicate the ingredients/recipes they use in cooking these vegetables. Water, salt, soda (sodium bicarbonate) and groundnuts were the main ingredients used. A few households $(25 \%)$ indicated using cooking oil. Water and soda were the only ingredients used in cooking Abelmoschus esculentus by most households (65\%).

Majority of households (Over 70\%) consumed ALVs as relish accompanied by nshima, a thick porridge, made mainly from staple food crop maize. In all the cases all household family members consumed vegetables. In some cases however, it was revealed that men might decline to eat Abelmoschus esculentus.

Most households (60\%) indicated appreciation and knowledge of the nutritive value of fresh vegetables while fewer $(50 \%)$ said so for dried vegetables. This may suggest that households were aware of nutrient losses in preserved vegetables arising from the drying process. Households from Hoffmeyer community and to some extent those from Chikumbi area seemed more knowledgeable than those from Sub centre. 


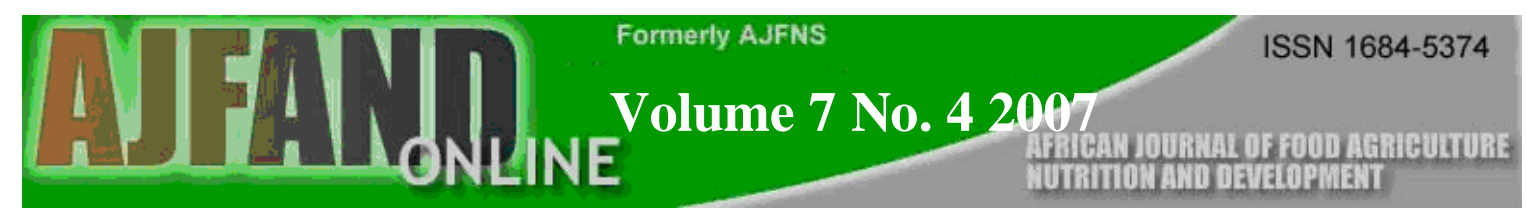

Figure 6: Documentation of the recipes for the African Leafy Vegetables.

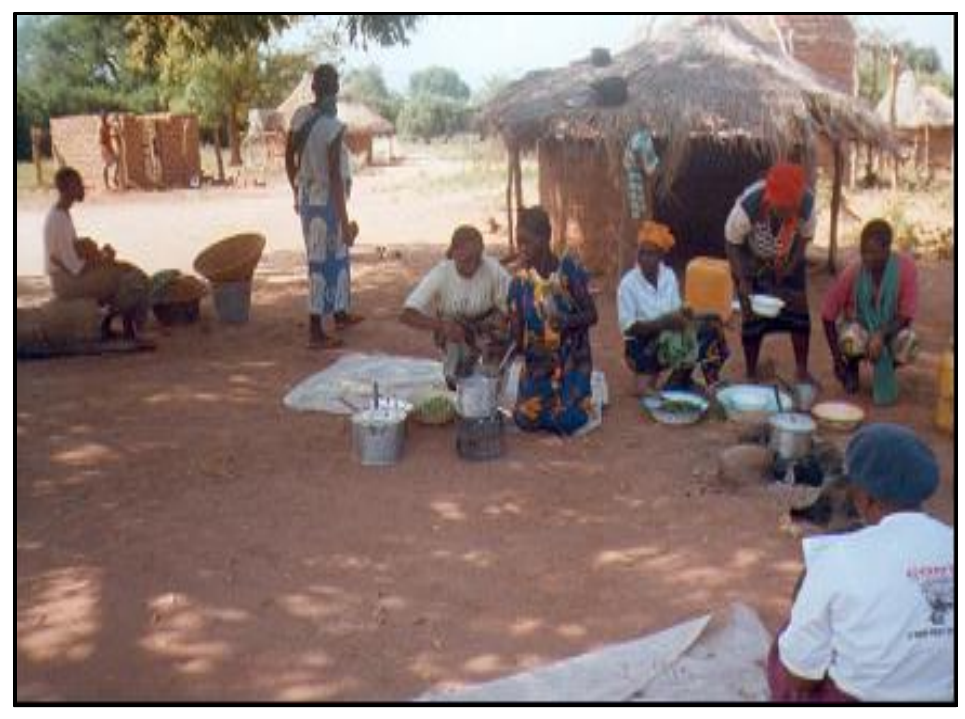

\section{MARKETING OF ALVS IN SUPERMARKETS}

A survey of formal marketing of African Leafy Vegetables was undertaken in Lusaka targeting major supermarkets such as Melisa, Shoprite, Embassy and Woodlands Berries. The survey aimed to collect information pertaining to types and forms of ALVs marketed, packaging, quality assurance, seasonality of supply, and consumer preference.

The findings of the market survey indicated that most of the supermarkets source their supplies of these vegetables from local farmers in the peri-urban areas of Lusaka.

The supermarkets ensure that vegetables ordered are of good quality and are kept in hygienic conditions. In most cases the vegetables are sold off within 2 days of getting the supply otherwise the vegetables are discarded. Vegetables are packaged in $1 / 2 \mathrm{~kg}$ bundles and sold between 500-800 Zambian Kwacha, equivalent to $25-30$ cents (US Dollar).

In terms of availability it was found that supermarkets get ALV supplies throughout the year. The vegetables were however said to be more abundant during the rainy season. From the experiences of the supermarkets it appears the most preferred ALVs by consumers are Abelmoschus esculentus, Amaranthus spp., and Cucurbita spp. 


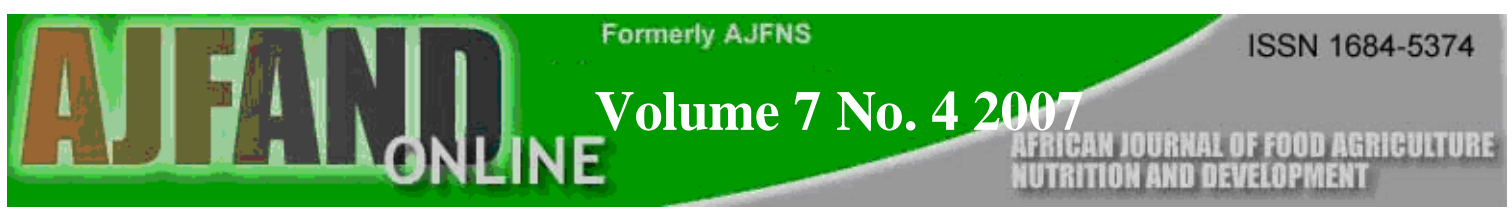

\section{DISCUSSION}

\section{Genetic Diversity of Priority African Leafy Vegetables}

In general it could be said that the cultivation of ALVs is more common in the surveyed communities compared to exotic vegetables. It was surprising that Hoffmeyer which is more of a rural setting had the lowest percent of households cultivating ALVs. This may however be explained by the presence of a long standing tradition of home gardens locally known as 'dimbas' in the area as in most parts of Eastern province of Zambia.

It appears that infraspecific variation or diversity is lower in those ALV species that are sometimes handled as semi-cultivated and weedy or wild, probably because they have not gone through much human selection. The number of commonly cultivated varieties was even lower compared to the possible numbers known to exist. There were for instance no more than two commonly cultivated varieties for all the priority ALVs in all the communities.

\section{Seed Supply System}

The survey results showed that small proportion of households obtained the seeds of various ALVs from outside their communities. A higher incidence of seed purchase from within communities for Brassica carinata is probably due to the fact that this vegetable species is readily available on the market competing favourably with some of the commonly grown exotic leafy vegetables such as Brassica napus.

The prevalence in local exchange of improved seed of ALVs in Chikumbi and Hoffmeyer, either through free gifts from neighbours/relatives or through purchases may indicate a higher level of production of these vegetables for commercial purposes than in Sub centre (Figure 4). This may also indicate potential for local seed production and marketing within the community. The low levels of seed exchange among households within the community for Sub centre may be as a result of the subsistence nature of production of the ALVs in that area.

\section{Harvestable and Edible Parts}

Tender leaves may be preferred for harvesting in Brassica carinata probably because older leaves tended to be tough and bitter and therefore less palatable. 


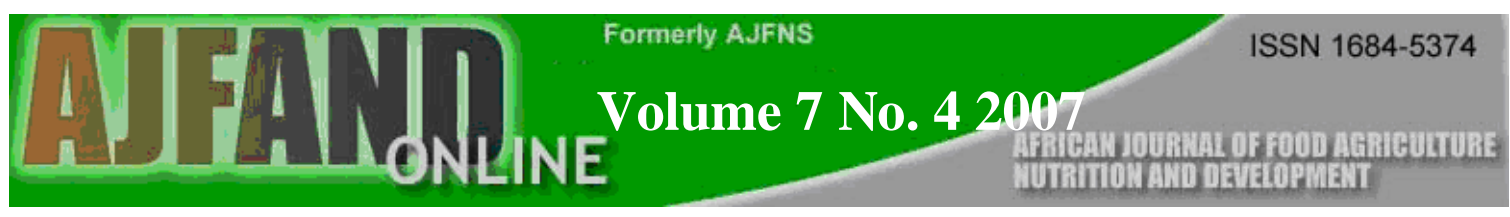

It is not common to harvest leaves together with flowers, as most people would want to retain flowers for seed bearing.

It would appear that in Hoffmeyer and Sub centre households rarely harvest fruits of okra only for own consumption. However, across the communities fruits are harvested largely for sale either fresh or dried.

Most of the harvested flowers in pumpkins are males as female flowers are deliberately left to bear fruits. This however does not seem to pose problems, as male flowers tend to be predominant in the pumpkin varieties used for vegetables.

When harvesting vegetables precaution was taken to avoid over harvesting in order to allow for easy regeneration and continued growth of the plants.

The number of children involved in the harvesting of Abelmoschus esculentus and Cucurbita spp.is relatively lowers probably due to the fact that these vegetable species need great care in order to enable the plant bear fruits. The involvement of men in the harvesting of vegetables is minimal and may only be involved when they harvested vegetables are meant for sale.

\section{Processing and Preservation Methods}

The survey results showed that preservation of some ALVs for consumption and sale during lean periods was an important activity across communities. As documented [4] the process leading to the preservation of ALVs follows a series of steps including harvesting, cleaning, cutting, blanching, sun drying and storage. It was common practice across the communities to preserve these vegetables when there was a surplus. In most cases Cleome gynandra and Amaranthus spp were not preserved in Hoffmeyer as most households preferred consuming them as fresh vegetables. Majority of households in Chikumbi (65\%) and Sub centre (95\%) indicated that they dried Amaranthus spp and Abelmoschus esculentus without blanching. However, in preserving Brassica carinata, Cleome gynandra, Cucubita spp and other local vegetables, blanching is followed by sun drying across the communities as the case when preserving any other vegetables [5], [6]. Blanching of leafy vegetables improves colour and carotene retention due to inactivation of enzymes but causes losses of ascorbic acid (vitamin C).

A variety of drying surfaces were used for drying these vegetables including man made such as reed mats and sacks, which are either placed directly on the ground or on raised platform locally known as 'Thala'. Naturally occurring flat stone surfaces are taken advantage of and used as drying surfaces where these are found. The drying process is said to be faster on the stone than the mat or sack. 


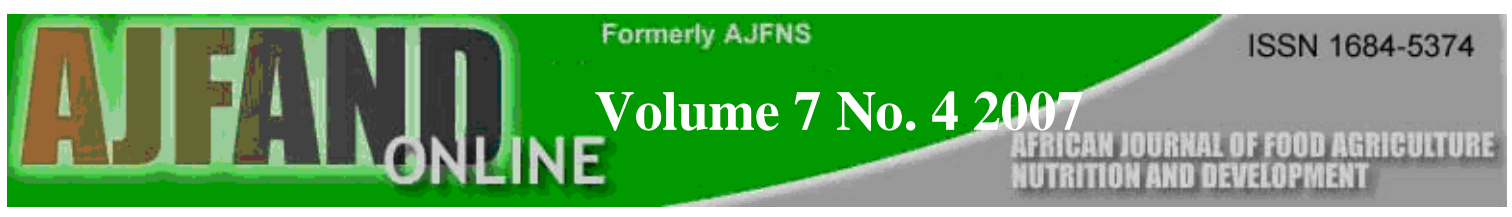

Across the communities, preserved ALVs are stored in polypthylene plastic bags.. High Density Polyethylene (HDPE) plastic bags, tightly sealed could also be used to store dried vegetables. HDPE are a relatively good barrier against air, moisture and odours [7]. Moisture, air, dust and odours if allowed into the dried vegetables could speed up deterioration of the vegetables and the expected shelf life may not be attained. In addition, HDPE is a strong film that gives a strong heat seal and withstands puncturing and tearing [7]. This property could be very useful as preserved vegetables often get attacked by rats and insects during storage in these communities. Traditionally, some households store their dried vegetables in 'Chikwati', a baggage made from broad leaves of certain tree species, and in turn hanged in the roof inside the house or put in the Crib.

\section{Preparation Methods}

Processing and Preparation of African Leafy Vegetables (ALVs) is a critical factor in the promotion of the production, consumption and conservation of these vegetables.

Majority of households indicated that preparing these vegetables either in the fresh or dried form was easy except for Cleome gynandra which was difficult mainly on account of the need to reduce the bitter taste through repeated decanting of water during boiling thus taking long to cook.

Using soda introduces a characteristic taste, which most people prefer. Salt is added to relish for taste while groundnuts and cooking oil are important ingredients in vegetable preparation as they increase the nutrient density and enhance palatability. In addition oil aids absorption of fat-soluble vitamins such as vitamin A, which can be obtained from vegetables from their precursor --carotene. The type of ingredients used to some extent also determines the dietary quality of these people since other nutrients needed by the body are provided by vegetable relishes.

Although different communities in Zambia have their own traditional methods for processing and preparation of these vegetables, there has been limited documentation of such information. As observed [8] changes in the food cultures that have taken place over the years pose threats to the continued existence of local knowledge pertaining to traditions of food preparation and processing.

\section{Consumption of the ALVs}

Although ALVs are consumed as relish accompanied by nshima, a thick porridge, made mainly from staple food crop maize, this could be consumed 


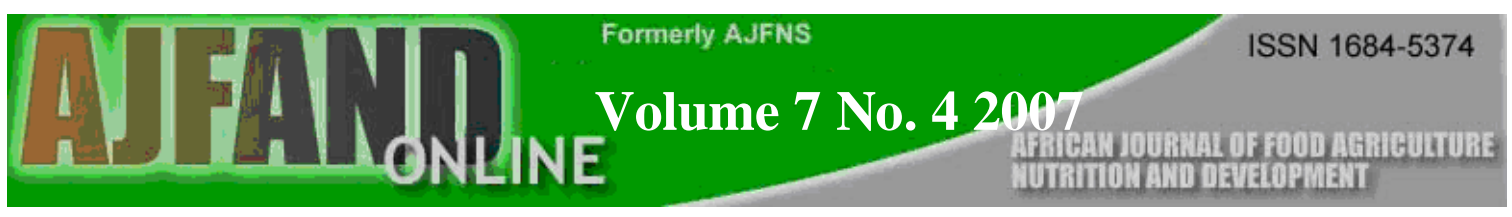

unaccompanied during periods of the year when there is a shortage of maize meal.

Although the importance of leafy vegetables in human nutrition lies in provision of vitamins, especially vitamin $\mathrm{C}$, they contain other nutrients such as carbohydrates, minerals and to small extent protein. Households from Hoffmeyer community and to some extent those from Chikumbi area seemed more knowledgeable than those from Sub centre. The protection of the body against diseases and infections, increase of blood and provision of energy to the body were mentioned as some benefits that can be derived from eating vegetables.

\section{Marketing of ALVs in Supermarkets}

The growing demand for the ALVs by people especially in the peri-urban and urban areas and availability of niche markets in major cities and towns provide an opportunity for the promotion of production of these vegetables.

\section{CONCLUSION AND RECOMMENDATIONS}

The Household survey revealed that majority of households in the selected target communities depends on agriculture for their livelihoods and that the selected priority African leafy vegetables (ALVs) are widely utilized though to varying levels.

Leafy vegetables in general play an increasingly important role as source of income in the target communities, especially those near major towns and cities. Improved access to urban markets by the rural communities has the potential of stimulating production of ALVs. Promotion of ALV production in peri-urban areas with easy access to urban markets has therefore a higher chance of producing positive results in Zambia.

In general ALVs in the target communities are grown and more available during the rainy season while exotic commercial vegetable species such as rape and cabbage which are usually produced for sale are grown during the dry season. Interventions aimed at promoting the production of ALVs during the dry season along side some of the traditional commercially grown vegetables are recommended

The survey has also revealed that some priority ALVs such as Amaranthus spp. and Cleome gynandra are to a large extent treated as semi-cultivated and weedy plants in Zambia. This has, to some extent contributed to the low production levels as well as the relatively low genetic variability within species. Crop improvement in 


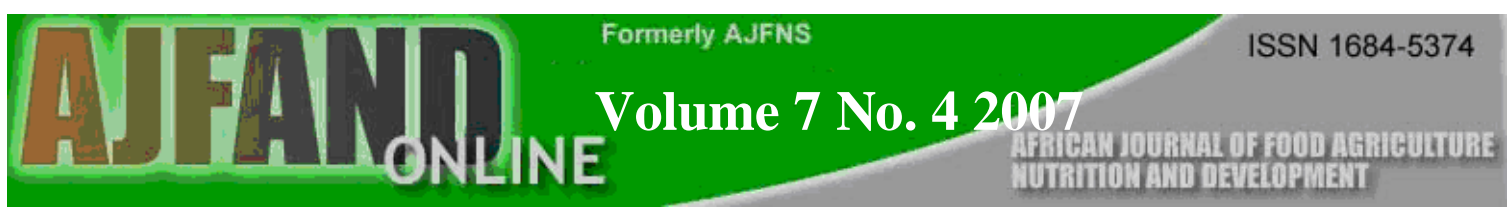

these ALV species would therefore require an infusion of germplasm from sources outside the country.

It is clear from this study that farmers in the target communities have no access to improved varieties of the priority ALVs and that seed for these is obtained mainly from locally saved seed within communities. The study has further pointed to an emerging local seed trade in which Abelmoschus esculentus and Brassica carinata are the main crops involved.

It is evident that there is very limited use of inorganic fertiliser but more use of organic sources in the production of ALVs. This provides a good opportunity for the promotion of organic farming that could be a platform for a market niche for most rural and peri-urban households.

The study has highlighted the role women play in agriculture in general and in the production of food crops in particular. The cultivation and in particular the harvesting of ALVs is mainly undertaken by women in the target communities. Men are beginning to get involved where these are grown for sale.

All the priority ALVs included in this study are processed for preservation, though to varying degrees, through sun drying either directly or after blanching. There is need to assess the nutritive status of the preserved vegetables with a view of improving the processes and minimizing nutrient loss or degradation.

In rural communities preserved vegetables are normally meant for own consumption but some of it is now finding its way at markets for sale. The amounts of vegetables preserved do not normally last the entire dry season. The introduction of solar drier would hasten the drying process and therefore increase the amount of vegetables that are preserved.

There seems to be limited variation in the methods of preparation or recipes for most of the priority ALVs with the main ingredients being water, salt, soda (Sodium bicarbonate) and groundnuts. Recipe emphasis should be placed on use of ingredients such as cooking oil and groundnuts to increase the nutrient density of the vegetables.

The study showed that there is some modest level of appreciation on the nutritive value of ALVs among households in the target communities. There is need to intensify nutrition education on the benefit of fresh and dried vegetables.

Some local restaurants, including hotels are taking up the preparation of some popular African Leafy Vegetables and serving this to their customers. This 


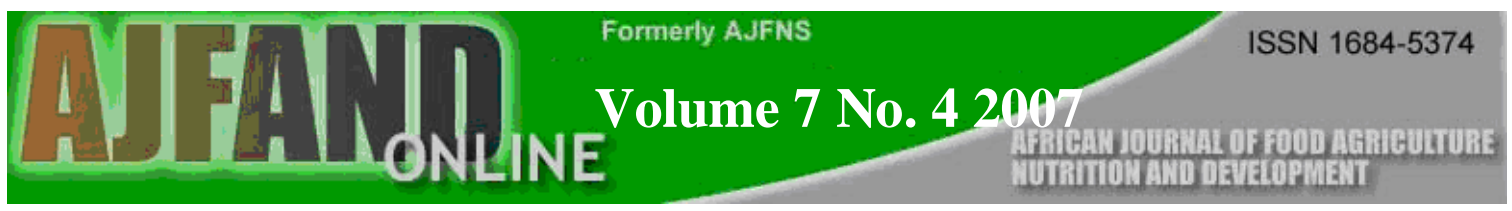

presents an opportunity that could be exploited in the promotion of these vegetables in terms of both production and consumption.

Preserved ALVs are traditionally, almost invariably, dried under direct sunlight. There is need to improve the drying methods taking into account hygienic considerations as well as the need to minimize nutrient degradation and loss. In this regard the use of solar dryers (Tray dryers) could be investigated. 


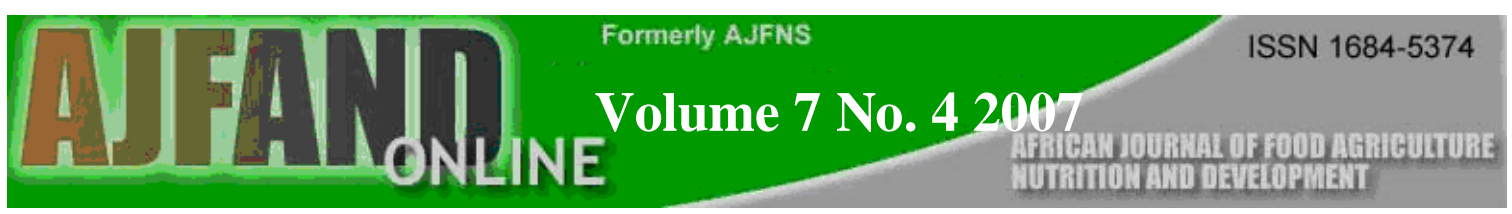

\section{REFERENCES}

1 FAO. Traditional Food Plants. Food and Nutrition Paper 42, Rome, Italy, 1988.

2 MAWD. Zambia Local Vegetables and Fruits, Handbooks for Agricultural Field Workers, Lusaka, Zambia. 1983.

$3 \quad$ Zulu RM Improving Food Supplies and Nutrition through Household and Village Level Processing and Preservation of Fruits and Vegetables in Eastern and Southern Africa, a paper presented at a Workshop held in Zimbabwe,12-16 February 1996. 1996.

4 Muntemba DC Small Scale Vegetable and Fruit Preservation in Zambia", pp 1, National Food and Nutrition Commission, Lusaka, Zambia. 1977.

5 UNIFEM. United Nations Development Fund for Women Fruit and Vegetable Processing. The United Kingdom. 1988.

$6 \quad$ Steinbuch E Fruit and Vegetable Processing in the Tropics. International Agricultural Centre (IAC), Wageningen, The Netherlands. 2000

7 Fellows $\mathbf{P}$ and $\mathbf{B}$ Axtell Appropriate Food Packaging, Amsterdam, The Netherlands, 1993; 63

8 Whitby $\mathbf{P}$ Zambian foods and Cooking, National Food and Nutrition Commission, Lusaka, Zambia. 1973; 33 